\title{
Education and ICT-based self-regulation in learning: Theory, design and implementation
}

\author{
Ton Mooij
}

Published online: 6 August 2008

(C) The Author(s) 2008

\begin{abstract}
Pupils attaining relatively low or high standards compared with most other pupils may come to experience motivation and achievement problems leading to final dropout from education. To overcome these problems, a systemic educational approach is presented. Cognitive, social, motivational and self-regulative aspects of learning tasks and learning processes are related to instructional and wider educational contexts. The result is a 'contextual learning theory' which specifies three sets of educational conditions to improve learning: (1) differentiation of learning materials and procedures; (2) integration and support by Information and Communication Technology; and (3) strategies to improve development and learning. Information is provided about characteristics and development of pedagogical-didactic and software prototypes. The prototypes are tried out in practice in Dutch pre-school and primary and secondary education. First implementation results are discussed.
\end{abstract}

Keywords Education system - Self-regulation in learning · ICT-based learning · Improvement strategies in learning $\cdot$ Implementation in education

\section{Introduction}

Why are some of our pupils failing? Research on school dropout clarifies that a pattern of pupil, home or family and school variables is responsible for a long-term process characterised by various types of variables (Garnier et al. 1997; Loeber and Farrington 2001; Reich and Young 1975). This dropping out process is expressed in, for example low school motivation and achievement and in dropout percentages that

T. Mooij

OTEC, Open University of The Netherlands, Heerlen, The Netherlands

T. Mooij $(\bowtie)$

ITS, Radboud University, P.O. Box 9048, 6500 Nijmegen, The Netherlands

e-mail: ton.mooij@ou.nl

e-mail: t.mooij@its.ru.nl 
are relatively constant across time. Such problems have a negative effect on pupils, teachers, parents, schools and society alike. However, the initiation of many projects to intervene in this dropping out process (Alschuler 1980; Arbeitsgruppe Schulforschung 1980; Mooij 2005; US Department of Health, Education and Welfare 1973) has not resulted in substantial changes in the numbers of dropouts in various school systems (European Commission 2005).

In this paper the assumption is that a systemic educational approach could provide more with respect to the diagnosis, potential reduction and possible prevention of persistent educational problems. The goal is to provide an educational system analysis that will allow intelligent and coherent intervention and prevention of the problems expressed in low motivation and dropping out of pupils. To realise this goal I will clarify some systemic causes and processes that can be identified between educational and pupil characteristics. Both educational theory and practice can assist in developing, implementing and checking better learning methods and coaching procedures, particularly for pupils at risk. The systemic development approach will take time and require coordination, but is expected to result in better learning processes and outcomes than we are used to.

First, I will diagnose some systemic aspects of education that do not seem to optimise the learning processes and school careers of certain types of pupils in particular. Second, I will specify cognitive, social, motivational and self-regulative aspects of learning tasks and relate corresponding learning processes to relevant instructional and wider educational contexts. These theoretical notions are elaborated into an educational design with systemic instructional guidelines and multilevel procedures that may improve learning processes for different types of pupils. Internet-based Information and Communication Technology (ICT) also plays a major role here (Crosier et al. 2002; Wilson 1999). ICT can, for example link different types of information, for various learners or groups of learners, across time, instructional situations or places and media, in order to support pedagogically responsible self-regulation (Bennett et al. 2002; Kreijns et al. 2003). Third, I will report on some concrete developments made in prototype research and trials. Fourth, I will focus on some first experiences gained in Dutch primary and secondary educational practice with respect to implementation.

\section{Diagnosis: Some systemic problems in regular education}

\subsection{National organisation versus realisation in practice}

The many main features of organisation and content of learning in primary and secondary schools are comparable across many countries. On the one hand, regular education is characterised by nationally prescribed global attainment targets, core or compulsory school subjects and administrative and certification rules (Earle 2000). On the other hand, realisation of such characteristics in practice encounters problems related to differences between pupils, their home environments and their teachers and schools, which are relevant to learning processes and their effects. Nationally prescribed attainment targets require flexible adaptations to individual and group characteristics of the pupils and their teachers in particular. If this is not the case, 
such targets may be changed regularly because the intended effects did not sufficiently affect instructional processes, or did not yield the desired effects on pupils. One example from The Netherlands is the creation and-after some 10 years - the withdrawal of 'basic secondary education', a national core curriculum for the lower secondary educational sector (Roelofs and Terwel 1999; Roelofs et al. 2003). Another consequence may be that evaluation or assessment and certification, including national examination standards, may vary or be adapted to the pupils' mean attainment.

\subsection{Age-based grouping of pupils, learning content and assessment}

After entering pre-school, pupils of about the same age usually remain in the same group for the following years. However, pupils who are the same calendar age at 4 years differ in their psychological or competence development, ranging in 'psychological age' from about 2 to about 8 years (Mooij 2000). Alloway (2006) explains that there is a considerable degree of variability in working memory capacity at each age. In a class of 30 young children, working memory capacity differences correspond to 5 or 6 years of regular development between the highest and lowest scoring individuals. The problem then is that the differentiation provided in the education system does not cover the psychologically relevant differentiation required by the pupils' individual characteristics.

In psychological tests, the actual performance of a child is usually expressed as the deviation from the mean performance of his or her age-mates, i.e. the 'population mean' or 'norm' (Kemp 2000). Most children perform around the mean of their age with respect to domains of competence such as general IQ or more specific language, arithmetic, social, emotional or motor domains. A smaller proportion of children will achieve at a very low ability level and another small proportion will achieve at a very high ability level. In age-based classes, then, pupils scoring in the lower left part of the ability curve will usually have the lowest achievement and get the lowest or insufficient school marks. This will not motivate them to continue their education (Beirn et al. 1972; Goleman 1995). The pupils in the lower right part of the ability curve will be confronted with activities that demand too little for their level of competence (Durkin 1966; Gallagher 1975; Mooij 1992).

Another procedure to assess the performance of a child can be based upon a specific 'criterion' or one or more series of tasks that are psychometrically evaluated to be relevant from, for example a mastery point of view. The child's performance is then evaluated against a concrete absolute standard, which can be based in a specific curriculum or used in an individual education plan. Criterion-based learning may help a low ability pupil to continue making progress in his or her development or learning and to be motivated to continue in school at other competence levels than a high ability pupil.

\subsection{Norm-based selection and 'underachievement' of low and high ability pupils}

Traditional pupil monitoring systems are often aimed at general concept validity, measured independently of specific educational methods or school books. These systems use the age-based organisation of pupils as the basis for a norm-based 
evaluation of the results of individual pupils, thereby reducing the possibility of criterion-based educational tools or programmes that offer effective and timely support to pupils at risk. Children achieving well below their age mean may have innate or development disabilities or physical handicaps. These children are more vulnerable than are other children when they go to pre-school or school (Hille et al. 1994). They often require extra assistance at home or specific instructional or organisational arrangements at school (Meijer et al. 2003). In many countries, specific groups of these children are excluded from mainstream education and referred to special education (European Commission 2005). Other indications of low ability or achievement can be found in social/emotional or behavioural problems. In addition, children from socio-economically disadvantaged homes or from ethnic minorities usually perform in the lower left region of the ability curve.

In the Canadian Education Act, high ability pupils are defined as those who display 'an unusually advanced degree of general intellectual ability that requires differentiated learning experiences of a depth and breadth beyond those normally provided in the regular program to satisfy the level of potential indicated' (Grayson 2001 , p. 123). By applying a current convention, the upper $3 \%$ of the population can be defined as highly able with respect to at least one domain of competence. In this situation, at least one out of every 33 pupils is highly able. Statistically, every agebased school class will therefore have one or more highly able pupils. Given the learning potentials and capacities of high ability pupils, the functioning of such pupils in regular education should be a non-issue. We know that, already at the age of 4 years, highly able pupils may read, write, do arithmetic or perform exceptionally well in social, emotional, expressive or motor domains (Baroody 1993; Davis and Rimm 1985; Mooij 1999a, b). Pedagogically and psychologically, these pupils should be supported at and above their own levels of competence once they start pre-school (Colangelo et al. 2004).

In age-based pre-school and primary education, however, high ability children usually receive encouragement based on the characteristics of pupils of their calendar age, instead of on their own psychological or developmental age. They end up in a situation of instructional 'forced underachievement' that can explain the motivational and learning problems experienced by these children from the start of pre-school (Butler-Por 1987). Research on young children demonstrates that environmental variables influence the development of intelligence, particularly during the first few years of life (Mönks and Lehwald 1991). Mooij and Driessen (2008) carried out a secondary analysis of Dutch national cohort data, with a focus on high ability pupils in pre-school and primary school. Initial longitudinal results were based on the definition of 'underachievement', i.e. not achieving progress in learning according to IQ potential. In the field of language, this type of underachievement generally varied between $18 \%$ and $21 \%$; in arithmetic, it was between $14 \%$ and $17 \%$, with the phenomenon being fairly even across grades. Underachievement was relatively highest in the lowest ability group. However, underachievement increased in the higher ability groups the longer the pupils' school careers lasted. To illustrate this phenomenon, Mooij and Driessen (2008) grouped all pupils attending grades 2 and 4 in 2002 into deciles based on their ability score for language and arithmetic, respectively. The lowest scores were grouped into decile 1 and the highest scores into decile 10. The raw language and arithmetic scores for 
2002 and 2004 were converted into standardised scores or $z$-scores. The scores in 2002 were then subtracted from the scores in 2004. The means of these differential scores are presented in the graph in Fig. 1.

Figure 1 illustrates that, during the transition from grades 2 to 4 , the pupils who scored lowest in both language and arithmetic in pre-school grade 2 (deciles 1, 2 and 3 ) attained relatively higher scores in the period 2002-2004, whereas the pupils in deciles 6-10 had a relatively lower score in 2004. Moreover, the pupils in deciles 1 and 10 gained or lost the most, relatively speaking. The same pattern emerges, although it is less pronounced, during the transition from grades 4 to 6 . Here, the pupils in deciles 1 and 2 achieved higher scores in the period 2002-2004; the pupils in deciles 4-10 had a relatively lower score in 2004. Compared with the high ability pupils in grades 2-4, the high ability pupils in grades 4-6 no longer lost as much ground. Moreover, studies of only the highly able pupils revealed some statistically relevant relationships between changes in teaching situation characteristics and changes in the teacher's perception of the pupil's behaviour and functioning from 2002 to 2004. The results reflect the negative influences of, in succession, 'class size', 'age-based monitoring', 'class mean performance' and 'non-acceleration', on the transition of high ability pupils from pre-school to primary school.

\section{Conclusion}

It can be concluded that low ability pupils may be confronted with educational materials and procedures beyond their level of competence, whereas high ability pupils may be forced to work at competence levels that are too low for their capacities and potentials. This is true from the beginning of their educational career. Both low and high ability pupils can therefore be said to be 'at risk' in pre-school and in regular primary education. For low ability pupils this becomes evident, for example in the final report of the 'No Child Left Behind' task force in the USA (National Conference of State Legislatures 2005); with respect to high ability pupils, Purcell et al. (2002) discovered a huge gap between what schools or teachers in the USA do for high ability pupils and what is really required for those pupils to learn.

Fig. 1 Results of differences in $z$-scores (2004 minus 2002), for language (grades 2-4, grades 46) and arithmetic (grades 2-4, grades 4-6)

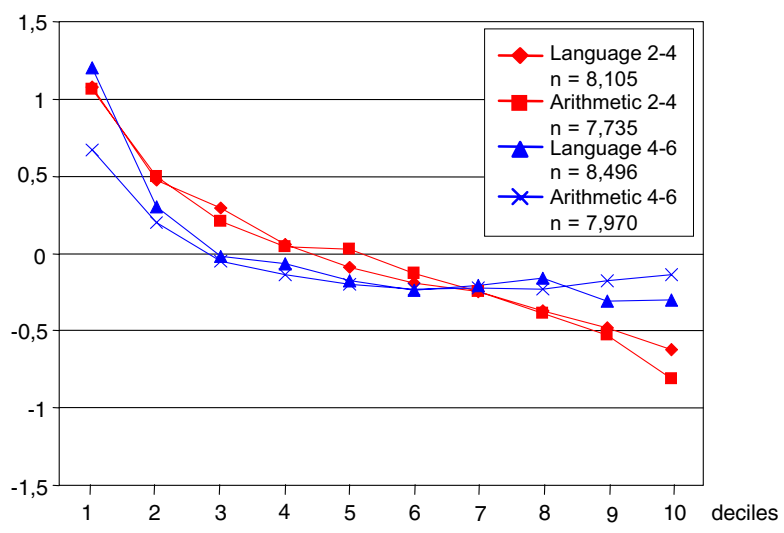


Pedagogically and psychologically, educational facilities should inspire and support each child's actual capacities and potentials in a social group context. Starting from their first day at pre-school, pupils are usually eager to move on to the next stages of competence. Teachers, parents and other professionals have to create situational conditions to continually facilitate pupils' motivation and responsible choices in self-regulation and learning behaviours. Adults are responsible for providing the necessary conditions, and pupils have to take over this responsibility from them during their school careers. As pupils are different from the very beginning, facilitating them differently means treating them equally (Gardner 1961).

\section{Theory: Self-regulation of learning in multilevel instructional contexts}

\subsection{Cognitive learning, learning tasks and instruction}

In 1965 Gagné defined learning as 'a change in human disposition or capability, which can be retained, and which is not simply ascribable to the process of growth' (p. 5). His learning theory was developed further by theorists and researchers who, for example, assumed that multiple elements of information are clustered into cognitive schemas that are used or modified in working memory during interactions with the environment or with other schemas, and can be automated and stocked in long-term memory. Ainsworth (2006) refers to some recent developments such as 'cognitive load theory', 'cognitive theory of multimedia learning', 'mental model construction of (symbolic) representations', and modelling of 'learning with multiple representations'. Van Merriënboer (1997) developed a 'four-component instructional design' model to emphasise the use of adequate instructional features and authentic and complex learning tasks. Instructional design should focus on a combination of performance support and fading, by scaffolding whole-task practice. In this respect 'meta-cognitive knowledge' is 'the declarative knowledge one has about the interplay between personal characteristics, task characteristics and the available strategies in a learning situation' (Veenman et al. 2004, p. 90). These researchers demonstrated that meta-cognitive skilfulness is a general, person-related characteristic across age groups; it develops and contributes to learning performance, partly independent of intelligence (also Prins et al. 2006).

Meta-cognitive skilfulness seems to play a major role in the self-regulation of learning. Kalyuga et al. (2003) hypothesised that novice learners lack sophisticated schemas in their long-term memory, so instructional coaching or guidance is needed for the task at hand. Contrary to this, experts bring their existing cognitive schemas to the process of constructing mental representations of a situation or task; they do not need instructional guidance. However, if this guidance is given and experienced learners cannot avoid it, the redundant information may have negative working, motivational and other consequences. The result is 'cognitive overload', which actually blocks learning processes. The authors called this phenomenon the expertise reversal shift and reported supporting research. The instructional conditions relevant to this shift correspond closely to the characteristics of the instructional situation of 'forced underachievement' of high ability pupils discussed above. A comparable situation applies for low ability or 'novice learners' who are confronted with 
learning tasks at too high a level of cognitive complexity. Interactions between pupil and instructional characteristics at the pupil level are, therefore, particularly relevant to the development of individual competence and the corresponding feelings of competence and self-regulation.

\subsection{Integration of social, organisational and self-regulation characteristics}

Dillenbourg (2002) provides evidence that cognitive, social, instructional and organisational aspects of education are integrated in school. Different cognitive and social characteristics of the pupils and their home situations, and cognitive, social and organisational characteristics of the learning tasks and instructional situations stimulate different types of individual, collaborative and social comparison processes between the pupils involved (Davis 1966; Marsh et al. 1995). Blatchford (2003), for example, observed large and small classes of children aged 4-5 years. Compared with large classes, in small classes teacher-child contacts were more frequent and personalised, children were more likely to be on-task and children interacted less extensively with their peers with respect to both work and social contacts. This perspective agrees with the outcomes of research on differentiated collaboration in school practice between 7- and 9-year-old primary school pupils in Sweden (Bergqvist and Säljö 1998). The organisational structure greatly facilitated the transfer of many responsibilities from the teacher to the learners.

Underwood (2003) defined cooperative learning as learning in which learners work together in small groups to achieve a common goal; in doing this, they may choose to take responsibility for subtasks and work cooperatively, or they may collaborate and work together on all parts of the problem. Furthermore, learners working in small groups can take on different constructive or destructive roles in the learning processes. Underwood referred to resistance to group work because of 'freeloaders' or individuals who withhold effort if they can achieve their goal by letting others do the work, or because of plagiarism. According to Underwood, these problems are related to the way instruction functions. If individual and collective tasks or contributions to group work are not perfectly clear, or not clearly evaluated, feelings of competitiveness may preclude cooperative or collaborative work. This was also made evident by Kaplan et al. (2002), who showed that the classroom goal structure is related to pupils' patterns of learning and behaviour. Learning according to personal mastery goals was related to lower reports of disruptive behaviour, whereas learning in line with an individual performance-approach and performance-avoidance goals was related to higher reports of disruptive behaviour.

\subsection{A multilevel approach to instruction and learning for self-regulation}

Understanding and improving a pupil's learning processes and consequent school career then requires a more comprehensive, systemic approach to the relationships between instructional characteristics and learning processes. The systemic approach can assist in clarifying how processes take place between different types of variables, at specific instructional levels and between different instructional levels (Cronbach 1983; Lundy and Kilpatrick 2006). The main centres of learning are individual pupils; higher up, they are organised into small groups or classes. Classes are 
organised in school locations, or schools. Groups of schools, or schools and institutes for youth health care, can build a community, region or district, to provide for various community-related services. Regions combine to build the national level, which is the original level for national educational policy and inspectorate, assessment or support institutes. Still higher up, the international level is characterised by different international policy and government institutes.

Generally, the number and types of levels distinguished depend on the goal of an investigation or policy approach. Here, the main focus is on the lowest levels where various pedagogical, psychological, and instructional and organisational characteristics on the one hand, and diverse characteristics of learning processes and outcomes on the other, interact and produce more or less systemic variations in cognitive, social, behavioural, motivational, self-concept and self-regulation outcomes. Self-regulation refers to 'self-generated thoughts, feelings, and actions that are planned and cyclically adapted to the attainment of personal goals' (Zimmerman 2000, p. 14). In competence-based learning processes it is expected that, as a pupil exerts more control over the own learning processes, his or her degree of 'selfregulated learning competence' will increase; something that usually motivates the selection and carrying out of more complex learning tasks (Bowerman 1978; Van den Boom et al. 2004). In primary education, this theory is empirically supported by the establishment of longitudinal relationships between school subject-related task motivation values, academic performance and self-concept of ability (Nurmi and Aunola 2005), although this is not always verified (Spinath and Spinath 2005). Paying explicit attention to self-regulation of learning, for example training pupils in self-regulative and problem-solving competence (Perels et al. 2005), or supporting teachers in structuring pupils' self-regulated learning and deep-level processing, is assumed positively to affect pupils' self-regulative processes. Schunk (2005) emphasises that intervention studies will help to understand whether principles of self-regulation generalise across contexts. Self-regulation effects will become stronger and more valid ecologically as pupils are allowed more initiative and responsibility, given a clear pedagogical and coherent instructional structure throughout school (also Morgan and Kennewell 2005; Parkhurst 1922; Rozendaal et al. 2005; Zimmerman 2002).

At the pupil level, competence-based learning can then be characterised by the following cycle: (1) estimation of the difficulty level of one or more learning tasks, followed by the selection of tasks to be performed; (2) various types of support or coaching for learning or the carrying out of the learning tasks; and (3) assessment or evaluation of the learning results according to specific criteria or norms, followed by the selection of the next or of other types of tasks, which is (1) again. Increasing the possibility of achieving self-regulation or learner-control by these successive stages, or 'scaffolding', is expected to function as a main prerequisite for taking the next motivated and effective, or competent, learning steps. Figure 2 illustrates the theoretical cycle of learning task selection-coaching-assessment, and so on (see the three outside ellipses and black arrows).

Each of the three parts of the cycle can change from 'performed by or dependent on instruction of others' via 'performed by the learner himself or herself' to 'assisting the learning of peers or other learners'. The 'self-regulation process' in the middle of Fig. 2 clarifies that selection, coaching and assessment are coordinated 
Fig. 2 Self-regulation cycle of learning task selection, coaching, and assessment

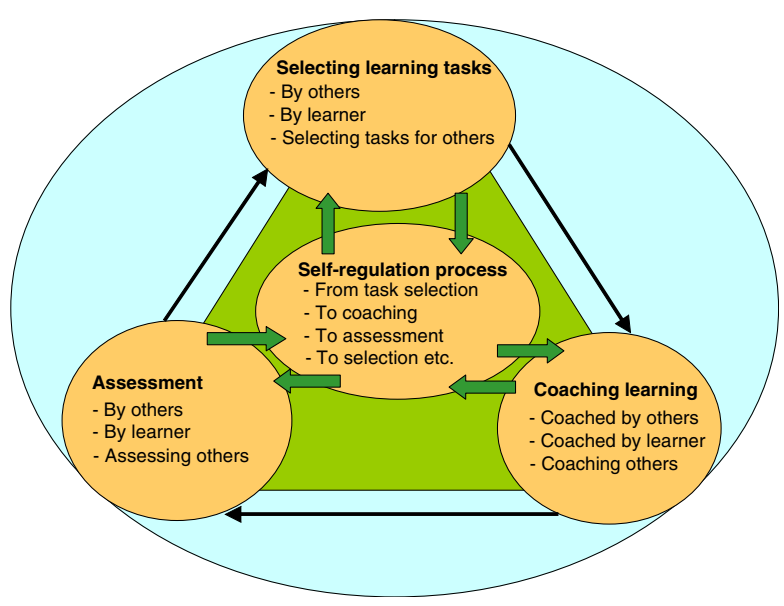

systemically and dynamically, to achieve the smooth functioning and increase in efficiency of relevant competencies. Each learning cycle depends on the adequacy of a learner's dynamic integration or 'self-regulation' of all process information with respect to task selection, coaching and assessment. The self-regulation process directs, supervises and checks concrete learning activities or tasks, monitors progress and analyses the potentials or difficulties of changing tasks, sets of tasks or the learning situation. This process seems to be essential for the person's identity as a learner: choosing or performing the next learning tasks will promote the learning outcomes and related benefits; not choosing or not performing the next learning tasks will-in the long run-result in the pupil dropping out of education.

As implied in Fig. 2, pedagogical, social, coaching and organisational characteristics play a role in the development of a pupil's self-regulation. The specification of such characteristics requires explicit relationships with various aspects of learning processes, in particular, diagnostic, instructional, managerial and systemic aspects. The first diagnostic aspect refers to the actual level of competence of a learner in a cognitive, social, emotional, motor, expressive or other relevant learning domain. Such a specification is required to estimate the relevance of the next learning activities or tasks, or processes. Diagnostics may be based on former learning results, screening of performance by one or more coaches or experts involved, testing with criterion- or norm-based instruments, or evaluations or assessments given by a teacher, coach, peer, learner, or a combination of the above.

The second learning aspect asks for the instructional consequences of the diagnostic value or indicator. Which specific didactic or instructional procedures should be assigned to learners with specific diagnostic outcomes? A diagnostic task can, for example, be part of a structured set of learning tasks or an 'instructional line'. In its turn, this line may be part of some sets of tasks or related instructional lines that can be combined to build a specific curriculum. In such a situation, the meaning of the diagnostic indicator is valuable in itself but it is also valuable from an instructional point of view because it may act as a criterion referring to specific curricular activities to be performed. 
Third, flexible and adequate management of both diagnostic and instructional learning aspects is necessary to evaluate and organise subsequent learning processes and learning progress in good time by individual pupils, small groups of pupils, groups or classes, school locations, schools, or other types of institutes or organisations. The managerial goal is to achieve multilevel transparency and balancing of individual and group or class-based learning progress and assessment, given the pedagogical choices made and the budgets available.

Fourth, systemic aspects of learning are at stake. A child belongs simultaneously to a family, one or more peer groups outside pre-school or school, and a class in primary or secondary school in which it spends many hours every week. Moreover, during the same time, the child may have contacts with, for example, youth health care professionals. It is possible to integrate these different worlds into the same set of learning processes by focusing on instructional and learning variables at the pupil level, small group level, class level and school level in particular. Diagnostic, instructional, managerial and systemic aspects can then be distinguished with respect to learning processes at the same level, but also between different levels simultaneously (Black et al. 2006; Cronbach 1983; James et al. 2006). The systemic relationships between these learning aspects can be elaborated in more detail with the aid of three educational conditional dimensions.

\subsection{Three educational conditional dimensions and the learning aspects}

As demonstrated above, a first important set of educational conditions to improve learning concerns the differentiation of learning materials and procedures. This dimension is necessary adequately to stimulate the learning processes of different pupils. Increasing differentiation in educational practice, however, places heavy demands on the information storage and processing capacities of teachers and coaches, pupils and parents (Kounin 1970). ICT can assist in registering, integrating, evaluating and reporting instructional and learning processes in various ways, across different situations (Crook 1998; Gustafson 2002). In particular, Internet-based software is - potentially - a very powerful tool for monitoring multilevel differentiation of instructional materials and procedures in relation to different learning processes and effects of individual pupils or various groups of pupils (Blumenfeld et al. 2000; Ely 1999; Sinko and Lehtinen 1999; Watkins 2001). If designed to support the diagnostic, instructional, managerial and systemic learning aspects referred to above in educationally integrated ways, ICT can act as a second 'educational conditional dimension'. The third educational conditional dimension is meant to empower further a combination of the first two dimensions. This dimension concerns guidelines for various but related strategies to improve development and learning, including self-regulation of learning. The improvement is expected to benefit not only the pupils in educational practice but also other persons or institutes involved, such as teachers, parents, schools and society at large.

The three educational conditional dimensions can be combined in theoretical sets of guidelines as modelled in Table 1. The 15 guidelines conceptualise a general educational design assumed to promote multilevel instructional learning processes for different types of pupils. Moreover, the model can be used to structure and coach the transformation of a school or group of schools from an age-based or less- 
Table 1 Educational conditional dimensions and modelling guidelines for learning

\begin{tabular}{|c|c|c|c|}
\hline \multirow{2}{*}{$\begin{array}{l}\text { Learning } \\
\text { aspect } \\
\text { (DIMS) }\end{array}$} & \multicolumn{3}{|l|}{ Educational conditional dimensions } \\
\hline & $\begin{array}{l}\text { Differentiation of learning } \\
\text { materials and procedures }\end{array}$ & $\begin{array}{l}\text { Integration by and use of ICT } \\
\text { support }\end{array}$ & $\begin{array}{l}\text { Strategies to improve } \\
\text { development and } \\
\text { learning }\end{array}$ \\
\hline Diagnostic & $\begin{array}{l}\text { 1.1. Identify a pedagogical- } \\
\text { didactic kernel structure for } \\
\text { different domains and } \\
\text { subdomains }\end{array}$ & $\begin{array}{l}\text { 2.1. Facilitate construction } \\
\text { and use of a pedagogical- } \\
\text { didactic kernel structure }\end{array}$ & $\begin{array}{l}\text { 3.1. Use a learner's entry } \\
\text { characteristics to } \\
\text { stipulate instructional } \\
\text { lines }\end{array}$ \\
\hline \multirow[t]{2}{*}{ Instructional } & $\begin{array}{l}\text { 1.2. Structure domains of } \\
\text { competence in terms of skills, } \\
\text { subskills and instructional lines }\end{array}$ & $\begin{array}{l}\text { 2.2. Enhance structuring, } \\
\text { transparency, and flexible } \\
\text { use of instructional lines }\end{array}$ & $\begin{array}{l}\text { 3.2. Create and control } \\
\text { pro-social relationships } \\
\text { in and around school }\end{array}$ \\
\hline & $\begin{array}{l}\text { 1.3. Include psychometrically } \\
\text { valid indicators to evaluate } \\
\text { learning progress }\end{array}$ & $\begin{array}{l}\text { 2.3. Facilitate individualised } \\
\text { instruction, collaborative } \\
\text { learning, and self-regulation }\end{array}$ & $\begin{array}{l}\text { 3.3. Use collaborative } \\
\text { didactic procedures to } \\
\text { stimulate self-regulation }\end{array}$ \\
\hline Managerial & $\begin{array}{l}\text { 1.4. Organise and match flexible } \\
\text { groups of learners and } \\
\text { teachers/coaches }\end{array}$ & $\begin{array}{l}\text { 2.4. Encourage differentiated } \\
\text { and multilevel evaluation of } \\
\text { learning }\end{array}$ & $\begin{array}{l}\text { 3.4. Concentrate teacher } \\
\text { coaching on those } \\
\text { pupils most in need of } \\
\text { this }\end{array}$ \\
\hline Systemic & $\begin{array}{l}\text { 1.5. Use integrated systems for } \\
\text { monitoring, evaluation, and } \\
\text { administration }\end{array}$ & $\begin{array}{l}\text { 2.5. Integrate instruction and } \\
\text { learning across different } \\
\text { contexts and points in time }\end{array}$ & $\begin{array}{l}\text { 3.5. Apply multilevel } \\
\text { indicators to improve } \\
\text { instruction and learning }\end{array}$ \\
\hline
\end{tabular}

differentiating instructional system into a more differentiating instructional system, with more optimal learning processes and effects.

\subsubsection{Differentiation of learning materials and procedures}

In Table 1, the first and diagnostically relevant differentiation guideline (1.1) refers to the specification of a 'pedagogical-didactic kernel structure' of competence domains, including the most relevant concepts and their measurement or evaluation. Competence domains include general intelligence, language, social-emotional performances, arithmetic/mathematics, physical-medical aspects, general psychological characteristics, and motor activities (Byrne 1998; Gallagher 1975). Such domains can be further specified into subdomains, and so on: see Fig. 3. An example is given by Sternberg and Grigorenko (2002), who defined successful intelligence as 'the ability to succeed in life according to one's own definition of success, within one's sociocultural context, by capitalizing on one's strengths and correcting or compensating for one's weaknesses; in order to adapt to, shape, and select environments; through a combination of analytical, creative, and practical abilities' (p. 265).

The second, instructional differentiation guideline (1.2) focuses on the curricular relevance of the pedagogical-didactic kernel structure. Diagnostic indicators from competence domains or subdomains have to be integrated with specific corresponding sets of curricular learning tasks and activities. These curricular tasks and activities then indicate the competence level of the skills or subskills required for the relevant learning processes. An example is given below in Fig. 4 (see Section 5). A specific set of curricular tasks or activities, including the diagnostic indicator(s), builds an 'instructional line' which is assumed to be characteristic for a specific level 


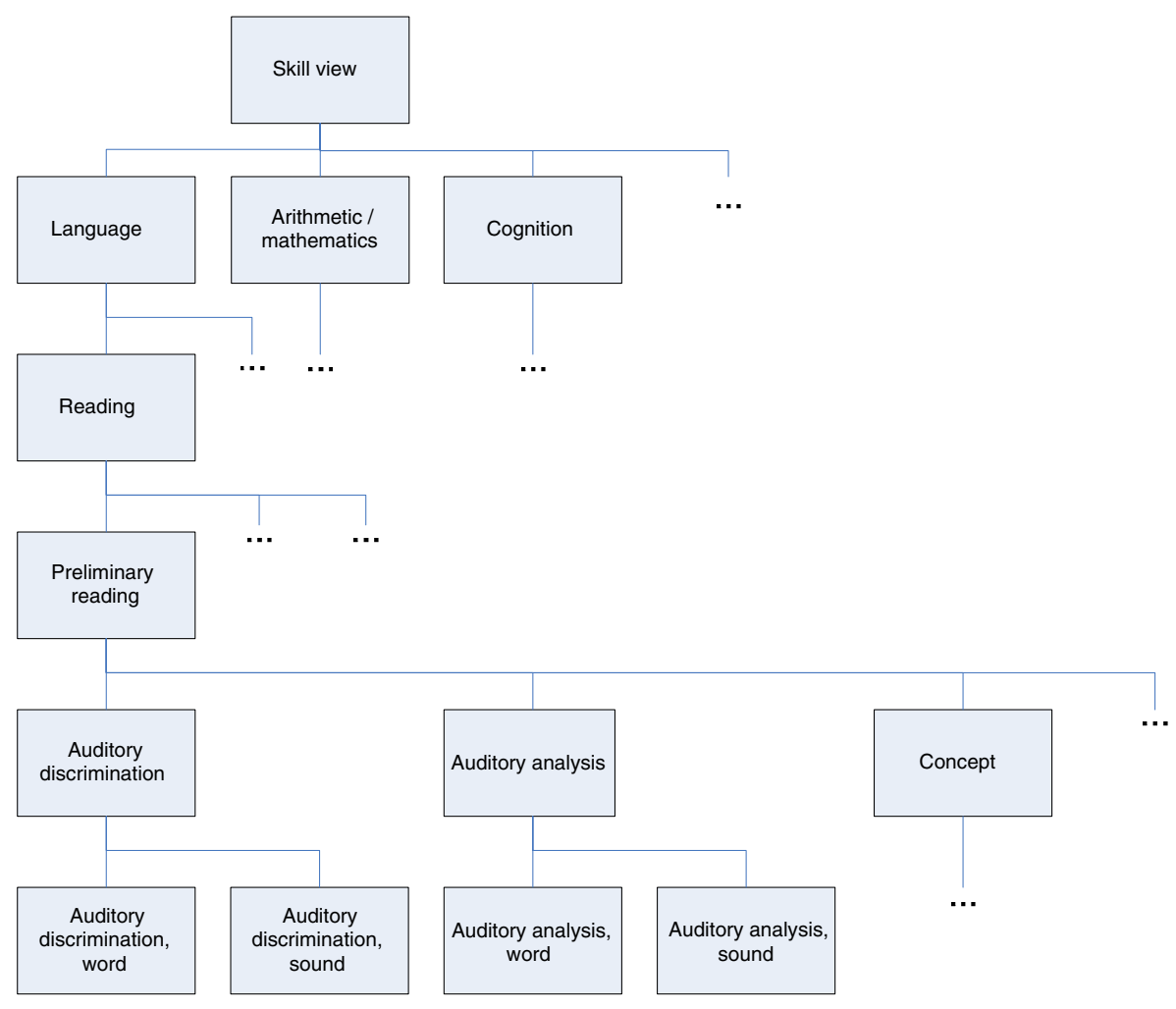

Fig. 3 Competence domains/subdomains of the pedagogical-didactic kernel prototype

of competence, or is validated as such. Such a line can be composed of learning tasks or activities taken from different competence domains, skills or subskills. Moreover, collaboration between different disciplines, societal sectors or professions can be made concrete, for example regular education and special education, education for high ability pupils, vocational education, youth health care, developmental psychology and pedagogy.

Third, integration of psychometrically adequate measures in instructional lines will greatly enhance instructional support for achieving and evaluating continuous learning progress from both individual and group or collective points of view. This relevance was demonstrated above in the discussion of norm versus criterionreferenced testing and in the referral of a pupil to special education or high ability facilities.

The fourth guideline explains how adequately to organise and match learners into flexible groups of learners, with various types of teachers or coaches, in order to optimise learning processes and outcomes. In practice, this includes flexible management and the evaluation of specific combinations of learners or types of learners with specific instructional lines or sets of these lines, given the staff, materials and other resources available (Brush and Saye 2001). Furthermore, in addition to activities required within the official curriculum, many nonofficial or non-compulsory activities can be chosen or developed by the learners 
themselves, and be evaluated by the learners or in cooperation with, for example, the teacher.

The fifth conditional guideline is the systemic concentration on the adequate linking and integrated functioning of the diagnostic, instructional and managerial differentiation aspects at the levels of the individual, small group, class and school in particular. This can be achieved by adequate collaboration between relevant persons, professionals and institutes, and by the creation and use of integrated software systems for monitoring, evaluating and administering the various multilevel types of information.

\subsubsection{Integration by and use of ICT support}

Internet-based ICT can register, connect, monitor, analyse or evaluate, administer or report on various types of information, provided or requested at different places or different times. An example is the educational information about one pupil that is provided by the pupil, the family of the pupil, teachers and other professionals involved in the various instructional and learning processes. The same ICT can also assist in informing teachers and learners about pedagogically or didactically relevant norms, or the results of comparing the learning outcomes of one or more pupils with specific assessments.

A first diagnostic guideline indicating these support functions of ICT is to assist in building and providing a pedagogical-didactic kernel structure at a 'national level' (see Table 1, guideline 2.1). This implies providing comparable support for all schools, teachers, other professionals and learners, although these users can select their own concepts and subconcepts for designing or creating their own curricular or learning domains, including levels of competence.

Second, according to instructional guideline 2.2, ICT can further help to structure, enhance the transparency and promote the use of differentiated curricular-based instructional lines and corresponding learning procedures across different educational levels and sectors. Various types of users in or around schools can select instructional lines, or create or adapt these lines to one or more pupils, small groups, classes, school locations or schools (Reynolds 2005).

Third, availability of an ICT-based pedagogical-didactic kernel structure allows the flexible adaptation of education to individual learning characteristics, for example learners' cognitive styles (Triantafillou et al. 2003) or individual education plans for either special education or high ability pupils (Mooij and Smeets 2006). The same may encourage pupils to create or design instructional lines for themselves, which will stimulate interdependent forms of learning and the pupils' self-regulation in various ways.

Fourth, from a managerial point of view, the possibility of screening or evaluating and organising learning processes or learning progress at different levels simultaneously is increased. This differentiated evaluation stimulates both individual learning and the provision of information about learning progress compared with other users, criteria or benchmarks.

Fifth, from a systemic point of view, Internet-based ICT in particular can integrate learning processes across different learning situations, either in school or-related to school-in families or youth health care support situations. ICT can systematically 
assist in transmitting data and providing feedback with respect to many different but related psychological, learning and instructional variables and their (possible) performance effects on individual pupils or groups of pupils at different levels (Clark and Estes 1999; Mooij 2004). The systemic ICT support will have more impact if this support empowers educational strategies to improve the development and learning processes of various types of pupils.

\subsubsection{Strategies to improve development and learning}

Here the first diagnostic guideline (Table 1, guideline 3.1) concerns the screening or evaluation of a pupil's initial or entry characteristics. This information can be used to check the parents' and the pre-school teacher's views of the child. Family and (pre-) school can then communicate about these views in a structured way and consider additional diagnostics or professional interventions where indicated, or discuss the assignment of regular or specific play materials or instructional (sub)lines just above the child's actual competence levels (also Bennathan and Boxall 1996; Tymms et al. 2000).

Second, from the instructional point of view, it is important to immediately create and mutually control pro-social relationships between all pupils, teachers and other professionals (Howard and Jenkins 1970; Mooij 1999c, d). Collaborative social and didactic procedures can be integrated into instructional lines to stimulate pro-social learning processes (Kaplan et al. 2002). Kreijns et al. (2003) specified how social collaboration and specific didactic support can result in positive group processes and outcomes. A combination of regular and risk-reducing pro-social activities or training programmes is often necessary to provide sufficient support for children, teachers and parents (Chen 2006; Hepler 1998; Salmivalli et al. 2005; Skinner et al. 1998).

Third, instructionally supported collaboration between pupils in small groups enables more motivating and more self-regulated learning processes and outcomes. Such instructional support is required, in particular, for pupils with special educational needs and for high ability pupils, as they differ considerably in initial or entry level of competence, magnitude of learning steps, speed and accuracy in learning processes, use of meta-cognitive strategies and degree of self-regulation during learning.

Fourth, from a managerial point of view, another potential benefit of collaborative self-regulation in small groups may be that this type of organisation enables the teacher to concentrate on those pupils most in need (Meijer 2003). Pupils who are able to self-regulate or use ICT as elaborated here can, for example, use the pedagogical-didactic kernel structure to design, monitor and evaluate their own learning processes in responsible ways.

Fifth, by using integrated and Internet-based ICT systems as indicated, from different systemic educational levels or perspectives, it is possible continually to improve the progress of each learner across different learning situations and educational sectors. This is what schools should do, at least from a legal point of view.

\subsubsection{Multilevel hypothesis}

Adequately differentiating instructional arrangements will result in qualitatively more supportive, more motivating and more productive learning processes and effects than occurs in age-based education (Schnotz and Lowe 2003). Internet-based support of the 
associated multilevel instructional management also creates more responsible and more self-regulative possibilities for learners than is possible without ICT (Kensing et al. 1998). Moreover, shifting into a more differentiating, ICT-based instructional managerial system allows teachers or coaches, other professionals and parents to concentrate differentially on relatively slower or less adequate learners; simultaneously, high ability pupils can effectively engage in more self-regulated learning processes. As this is achieved in educational practice, the age-based or less-differentiating educational system is transformed into a differentiated, ICT-based, instructional managerial system. The expectation is that this transformation will improve the learning processes and educational careers of low and high ability pupils in particular. A general multilevel hypothesis expressing this transformational expectation can be formulated:

As differentiation of learning materials and procedures, integration by and use of ICT support, and strategies to improve development and learning are achieved at multiple levels, it is expected that improvements will take place in multilevel differentiation and evaluation of learning processes. This will result in better self-regulation and learning outcomes, particularly for learners who initially deviated most from the mean in their group or class, or from their peers' norm.

\section{Development: Prototype research and trials}

\subsection{Differentiation of learning materials and procedures, and ICT support}

Differentiation of learning materials and procedures first of all required development of a prototype of a 'pedagogical-didactic kernel structure' (PDKS; Table 1). Moreover, the corresponding Internet-based support had to be elaborated by developing a software prototype concentrating on 'diagnostic, instructional and managerial systems' (DIMS). The prototyping of both PDKS and DIMS was carried out in different phases.

First, guidelines 1.1 and 1.2 in Table 1 were made concrete as follows. An inventory of Dutch instruments and tests for young people aged 0-20 resulted in a set of hierarchically structured competence domains and subdomains. The main domains contain skills related to language, arithmetic/mathematics, general cognition, socialemotional performance, physical-medical aspects, general psychological characteristics and motor activities. The prototype reflects a multidisciplinary classification based on measurable skills and subskills, with a focus on education. A 'skill view' presents skills in a hierarchical order. The main characteristic of this view is that it applies in all instances or at all schools. An example of a skill view concentrating on a part of the language competence domain is given in Fig. 3. In this structure, the only relationships are hierarchical ones. For example, a learner who is able to perform all subskills (e.g. 'auditory discrimination word' and 'auditory discrimination sound') has reached the respective skill level ('auditory discrimination'; see Fig. 3).

ICT features can be of unique relevance because they allow easy manipulation and immediate demonstration of such ordering structures. In this respect, DIMS was designed to produce a 'skill order view' that can describe conditional dependencies between PDKS skills from one or more domains. This allows the integration of skills 
from different domains into tasks that vary in complexity. The screen dump of DIMS in Fig. 4 presents a skill order view with respect to the early learning and production of sentences. The rectangles represented in Fig. 4 illustrate that, from left to right, 'internal representation of information' and 'production of sounds' (far left) are conditional to the production of 'one-word sentences', which in its turn is conditional to 'two-word sentences'; these are conditional to 'more-word sentences'.

Figure 4 illustrates the use of PDKS-based concepts and subconcepts relevant to learning processes. These (sub)concepts can be diagnosed or evaluated by psychometrically valid indicators which are related to curricular materials and specific learning tasks. The (sub)concepts and their ordering reflect, more or less, general anchor points of learning processes which, as much as possible, should be based on research. Schools or school managers, teachers, professionals from other institutions, pupils or parents, can use but not change such PDKS-based skill order information as given in Fig. 4. They can, for example, use DIMS to select one or more (sub)concepts and connect specific learning tasks or evaluation or diagnostic activities into self-made instructional lines leading to them. The instructional lines are then stored by the software and can be assigned to any pupil or group of pupils, or be changed whenever this is desired.

It is thus possible to link fairly stable, general conceptual skill orders conceptualised within the PDKS with the situational or user-based selection of relevant parts of the PDKS at the work areas in or around schools. This characteristic of DIMS allows systemic flexibility, and changeability because of the characteristics of one or more pupils or teachers. The DIMS prototype thus enables user-based integration and evaluation of diagnostic or other psychometric checks related to specific curricular blocks. The instructions or instructional lines may refer to curricular and learning materials or procedures present in or around the classes or schools involved, so pupils need computer access only to get instruction or feedback. This procedure is expected to adapt to the functioning of young pupils in particular, to promote the attractiveness of learning because of the increase in didactical variations, and to make optimal use of available curricular and learning or other materials and procedures.

\subsection{ICT-based strategies to improve development and learning}

There are few suitable Dutch instruments for measuring children's pre-school entry characteristics. A psychometrically controlled screening procedure was developed earlier in longitudinal research involving 966 children, their parents and their teachers (Mooij 2000). The questionnaire can be administered by an infant day-care

Fig. 4 Skill order view: concepts ordered to indicate production of sentences

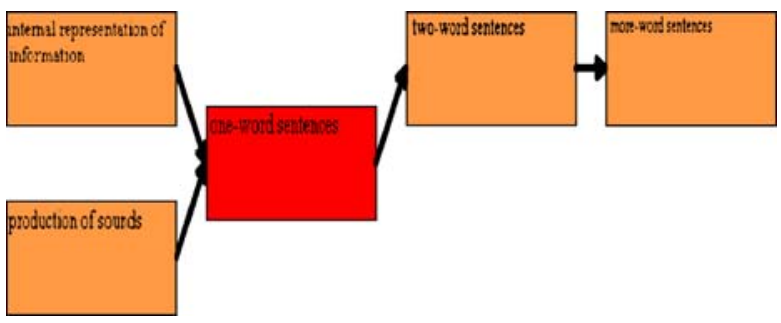


teacher when the child is about to leave the day-care centre to go to pre-school, by the parents when the child enters pre-school and by a pre-school teacher after the child's first few months in pre-school. The procedure estimates a child's level of competence in various domains by comparing their behaviour with the behaviour of same-age peers in general. This particular reference is used because this is the only comparison parents can usually make to evaluate their child's behaviour. The seven scales refer to the estimated level of, respectively, social interaction/communication, general cognition, language proficiency, (preliminary) arithmetic, sensory-motor level, emotional-expressive level and expected educational behaviour/motivation.

The screening of entry characteristics with the aid of DIMS also results in the presentation of different types of scale scores and diagrams for each behaviour domain. For example, per domain: a first score and diagram represent the age norm indicating the population benchmark; the second scale score and diagram indicate the parents' estimation of their child's performance compared with age-mates; the third score and diagram represent the pre-school teacher's estimation; the fourth score and diagram are given by the infant day-care teacher; and the fifth score and diagram represent the mean of the teacher's scores for the children in this class.

A teacher's didactic coaching of one or more pupils, but also the self-regulation of learning by one or more pupils, can be further assisted by DIMS-provided skill order views that indicate the actual level of competence and subsequent choices with respect to the next learning activities, either ordered into instructional lines or as separate activities. Such PDKS-based choices, or planned deviations from this structure, can support a very important, common frame of reference for collaboration between teachers, parents, pupils and youth health care or other advisory professionals. Therefore, the next development step was to initiate implementation of the PDKS and DIMS prototypes, and the guidelines set out in Table 1, in educational practice. The implementation and further development of both PDKS and DIMS should be realised in collaboration between research and teachers, pupils, parents and management in school locations or schools.

\section{Implementation: Changes in educational practice}

\subsection{Pre-school and primary education}

Collaboration with pre-school and primary teachers in three Dutch pilot schools resulted in specification of practical requirements and initial implementation of the PDKS and DIMS. Actual implementation commenced with the screening of entry characteristics of 4-year-old pupils who were about to attend pre-school (guideline 3.1 of Table 1 and Mooij 2000). The teachers, parents and day-care centre teachers first had to familiarise themselves with this type of intake. Then, DIMS was used to screen entry characteristics of incoming children-357 times in the period 2003-2005 (also Mooij and Smeets 2006). The practice experiences of these pilots can be summarised as follows.

The use and the results of the screening procedure helped both parents and teachers to gain a clear view of each child's entry characteristics. The persons involved agreed that the multiperspective screening helped them arrive at a more structured and comprehensive view of a child's levels of competence (also Cornell et 
al. 1994; Mooij 2002; Walker et al. 1998). Moreover, the use of DIMS and the PDKS facilitated more specific communication about the child, and more coordination of development and learning processes both in pre-school and at home (Blumenfeld et al. 2000; Mangione and Speth 1998). The outcomes of the screening procedure were used to assign specific playing or diagnostic and learning activities to specific children, as a basis for further pedagogical and didactic support. It was significant that other play and learning materials had to be introduced into the pilot schools, as it became evident that differences between pupils were more pronounced than the traditional materials had accounted for. Finally, the teachers became more interested than before in creating different types of small groups of pupils, as this organisational feature seemed to provide better conditions to foster pro-social and effective, self-regulative learning relationships between pupils.

In one of the pilot pre-schools, attention was drawn, in particular, to the prototype of the PDKS and the age-independent collaboration of pupils in small groups throughout preschool and primary school. As verified by the researcher's observation in practice, this school team developed a rather complete child-oriented curriculum (guidelines 1.1-1.4 of Table 1) to introduce and apply strategies to improve development and learning for all pupils present in the school (guidelines 3.1-3.4). With respect to the tasks and activities that are part of a pupil's weekly task schedule, the teachers initially place a pupil at a specific instructional or competence level. Thereafter, the pupil chooses one or more other pupils to cooperate with on the basis of the other pupil's or the other pupils' competencies. Each pupil is usually included in various small, collaborative groups of pupils. The self-regulation formulation for executing tasks or activities by the pupils is:

- What do you want to do? Decide for yourselves.

- Why do you want to work on this task or activity?

- How are you going to do that?

A pupil's work plan can be designed by the pupil for a longer period of time and for various areas of competence: expressive behaviour, arithmetic, language, motor behaviour and so on. Where necessary, a teacher advises or coaches. The teacher also checks the pupil's work plan for completeness of skills covered, strategies, and goals. In addition to the pupil's plan, the team also has a plan that sets out the skills and goals to be achieved for each pupil. To coordinate these plans, which may differ, the pupil, the parents and the team collaborate closely. Where necessary, external professionals are called in.

Furthermore, in collaboration with the pilot teachers from the three pre-schools involved, different examples of instructional lines for regular, special education and high ability pupils were developed and integrated into DIMS. However, actual use of this support by DIMS needs more implementation time in educational practice. In this respect, the development and implementation of the PDKS seem conditional to the implementation of corresponding ICT, which agrees with the assumptions of the successive modelling in Table 1.

\subsection{Secondary education}

A comparable programme to that in primary education was set up in Dutch secondary education. For sector-related and budgetary reasons, the innovation 
activities had to be split up. From the start of 2003, collaboration took place with three National Educational Advisory Centres in seven secondary school locations (most of these belonged to agricultural schools). Information about the project goals, procedures and results in the period 2003-2006 is available on the Internet ('Livelink': see https://livelink.groenkennisnet.nl/).

This project involved various innovation partners: seven school locations, each with some teachers and school management; all three National Educational Advisory Centres; the Ministry of Agriculture, Nature and Food Quality; a software development institute; and a research and development institute. The research and development institute had also designed a framework for concrete curriculum and software development, including evaluation procedures to structure the necessary implementation in practice. From the start of the project, however, discussions between the partners concentrated on the relevance of diagnostic features in the curriculum and the related development and implementation of specific evaluation or assessment aspects. These discussions reflected different notions and evaluations of, and different institutional positions with respect to, concepts such as 'natural learning' and 'new learning' (Mooij et al. 2000). The differences were mainly related to groupings of schools according to the educational policy of the specific Advisory Centre coaching the schools.

One main consequence was that diagnostic-based curriculum development and the corresponding implementation of continuous learning processes, either individually or in collaborative small groups of pupils, became blurred. The Advisory Centres decided to concentrate first on introducing ICT at the schools. This introduction and the follow-up implementation of ICT were successful, but the required curricular development and assessment has yet to take place. As noted in the introduction section already, it seems that specific educational projects do not usually contribute to a more systemic or integrated development of education.

\section{Discussion}

The starting points of this paper were long-standing motivation and achievement problems of pupils attaining relatively low or high standards compared with most other pupils, which may lead to final dropout of education. A systemic educational approach was introduced in an attempt to overcome such problems. Cognitive, social, motivational and self-regulative aspects of learning processes were related to instructional and wider multilevel educational contexts. Three theoretical sets of educational conditions to improve diagnostic, instructional, managerial and systemic aspects of learning for different types of pupils were modelled in Table 1. The sets concern: (1) differentiation of learning materials and procedures; (2) integration and support by ICT; and (3) strategies to improve development and learning. Development of pedagogical-didactic and Internet-based prototypes were subjected to implementation research in Dutch primary and secondary education. Given this state of play, some qualitative preliminary conclusions can be drawn.

First of all, the theoretical design of necessary instructional and organisational innovations to improve learning processes seems to be adequate in educational practice. The initial results in the pilot pre-schools and primary schools make 
concrete what may be meant by the 'value added' of schools. These first implementation experiences emphasise the importance of further initiatives and efforts, to improve education and learning in and around schools by combinations of pedagogical-didactic and ICT-supported features. Continuation and extension are also needed to check the learning processes and effects with low and high ability pupils.

Second, in pre-school, primary and secondary education, responsible collaboration between research and practice leading to system innovation requires some specific facilities: longitudinal planning and management of development and implementation time; repeated and structured discussions of, and concrete decisions about, educational and learning essentials and irrelevancies; initiation of 'evidence-based proofs of better practices'; and collaborative empirical evaluation of intermediate outcomes and planning of subsequent steps to be taken (Finn-Stevenson and Stern 1997; Jervis and Gkolia 2005; Zakopoulos 2005).

Third, differentiation of teaching-learning situations, differentiated assessments of learning progress and support by adequately designed Internet-based software facilities, indeed, constitute essential conditions for stimulating school motivation, achievement and responsible self-regulation of different types of pupils (also Baker et al. 1998; Collier 1994; Marshall and Drummond 2006; Merrill 2002). In the present research, however, the intermediate results as yet do not enable the testing of the hypothesis as formulated above against sufficient quantitative data. First priority has to be given to development and implementation of the multilevel innovation in more (pre-)schools.

Fourth, the pre- and primary school team that developed a more completely differentiated curriculum demonstrated that specification of instructional levels and social and cognitive roles of pupils from the very start at pre-school helps pupils to develop desired competences including self-regulation of learning processes (also Coie and Miller-Johnson 2001). A comparable conclusion was drawn by Gillies (2004) with respect to the effects of cooperative learning with small groups in secondary school. Compared with pupils in unstructured groups, pupils in taskstructured groups were more willing to work with others on the assigned tasks, they provided more elaborate assistance to each other, and developed a stronger perception of group cohesion and social responsibility. This is also in line with the experience and cognitive results gained in a 'computer-supported intentional learning environment' (see Lipponen et al. 2002).

For those pupils achieving relatively low standards compared with the other pupils, further research and development of instructional variables and cognitive learning is necessary. Alloway (2006), for example, claims that deficits in working memory appear to be unique to learning difficulties in literacy and mathematics, and are not found in problems of a behavioural or emotional nature. She states that little evidence exists that remediation or direct training of working memory skills leads to improvement in academic attainments and suggests reducing working memory demands in the classroom through four effective management approaches. These self-help strategies may promote the development of such pupils into relatively independent learners who are able to identify and support their own learning needs (also Kliewer et al. 2004). Another aspect of this line of research is to focus on the integration of pupils with emotional/behavioural disorders. Chen (2006) reviews intervention research on social skills development and summarises important 
outcomes. Such instructional specifications and learning processes could be supported by instruments like the PDKS and DIMS.

Finally, to help pupils who initially achieve well above most other pupils, it is necessary to design and check educational practices for high ability pupils. Research, in general, indicates that the educational performance of gifted pupils can be improved considerably (Brown et al. 2005; Scott and Delgado 2003). The required instructional and learning processes could be designed first of all by these pupils themselves, with the assistance of the PDKS and DIMS.

Open Access This article is distributed under the terms of the Creative Commons Attribution Noncommercial License which permits any noncommercial use, distribution, and reproduction in any medium, provided the original author(s) and source are credited.

\section{References}

Ainsworth, S. (2006). DeFT: A conceptual framework for considering learning with multiple representations. Learning and Instruction, 16(3), 183-198. doi:10.1016/j.learninstruc.2006.03.001.

Alloway, T. P. (2006). How does working memory work in the classroom? Educational Research and Reviews, 1(4), 134-139, (Accessed August 9th 2006 at http://www.academicjournals.org/ERR).

Alschuler, A. S. (1980). School Discipline: A socially literate solution. New York: McGraw-Hill.

Arbeitsgruppe Schulforschung (1980). Leistung und Versagen. München: Juventa.

Baker, J. A., Bridger, R., \& Evans, K. (1998). Models of underachievement among gifted preadolescents: The role of personal, family, and school factors. Gifted Child Quarterly, 42(1), 5-15. doi:10.1177/ 001698629804200102.

Baroody, A. J. (1993). Fostering the mathematical learning of young children. In B. Spodek (Ed.), Handbook of research on the education of young children (pp. 151-175). New York: MacMillan.

Beirn, R., Kinsey, D. C., \& McGinn, N. F. (1972). Antecedents and consequences of early school leaving. Educational Documentation and Information, 46(182), 1-116.

Bennathan, M., \& Boxall, M. (1996). Effective intervention in primary schools. Nurture groups. London: Fulton.

Bennett Jr, W., Schreiber, B. T., \& Andrews, D. H. (2002). Developing competency-based methods for near-real-time air combat problem solving assessment. Computers in Human Behavior, 18, 773-782. doi:10.1016/S0747-5632(02)00030-4.

Bergqvist, K., \& Säljö, R. (1998). Construction of curricular content in the individualised age-integrated classroom. Paper presented at the European Conference on Educational Research (ECER), September 17-20, Ljubljana, Slovenia.

Black, P., McCormick, R., James, M., \& Pedder, D. (2006). Learning how to learn and assessment for learning: A theoretical inquiry. Research Papers in Education, 21(2), 119-132. doi:10.1080/ 02671520600615612 .

Blatchford, P. (2003). A systematic observational study of teachers' and pupils' behaviour in large and small classes. Learning and Instruction, 13(6), 569-595. doi:10.1016/S0959-4752(02)00043-9.

Blumenfeld, P., Fishman, B. J., Krajcik, J., Marx, R. W., \& Soloway, E. (2000). Creating usable innovations in systemic reform: Scaling up technology-embedded project-based science in urban schools. Educational Psychologist, 35, 149-164. doi:10.1207/S15326985EP3503_2.

Bowerman, W. R. (1978). Subjective competence: The structure, process and function of self-referent causal attributions. Journal for the Theory of Social Behaviour, 8, 45-75. doi:10.1111/j.14685914.1978.tb00391.x.

Brown, S. W., Renzulli, J. S., Gubbins, E. J., Siegle, D., Zhang, W., \& Chen, C.-H. (2005). Assumptions underlying the identification of gifted and talented students. Gifted Child Quarterly, 49(1), 68-79. doi: $10.1177 / 001698620504900107$.

Brush, T., \& Saye, J. (2001). Defining hard and soft scaffolding in technology-enhanced student-centered learning environments. Paper presented at the conference of the Association for Educational Communications and Technology (AECT), November 8-10, Atlanta, GA. 
Butler-Por, N. (1987). Underachievers in School: Issues and intervention. Chicester: Wiley.

Byrne, B. (1998). The foundation of literacy. The child's acquisition of the alphabetic principle. Hove: Psychology.

Chen, K. (2006). Social skills intervention for students with emotional/behavioral disorders: A literature review from the American Perspective. Educational Research and Reviews, 1(3), 143-149, (Accessed 9 August 2006 at http://www.academicjournals.org/ERR).

Clark, R. E., \& Estes, F. (1999). The development of authentic educational technologies. Educational Technology, 39(2), 5-16.

Coie, J. D., \& Miller-Johnson, S. (2001). Peer factors and interventions. In R. Loeber, \& D. P. Farrington (Eds.), Child delinquents: Development, intervention, and service needs (pp. 191-209). Thousand Oaks: Sage.

Colangelo, N., Assouline, S. G., \& Gross, M. U. M. (2004). A nation deceived. How schools hold back America's brightest students (Volumes I and II). Iowa City: The University of Iowa, International Center for Gifted Education and Talent Development.

Collier, G. (1994). Social origins of mental ability. New York: Wiley.

Cornell, D. G., Delcourt, M. A. B., Bland, L. C., Goldberg, M. D., \& Oram, G. (1994). Low incidence of behavior problems among elementary school students in gifted programs. Journal for the Education of the Gifted, 18(1), 4-19.

Cronbach, L. J. (1983). Designing evaluations of educational and social programs. San Francisco: Jossey-Bass.

Crook, C. (1998). Children as computer users: The case of collaborative learning. Computers \& Education, 30, 237-247. doi:10.1016/S0360-1315(97)00067-5.

Crosier, J. K., Cobb, S., \& Wilson, J. R. (2002). Key lessons for the design and integration of virtual environments in secondary science. Computers \& Education, 38, 77-94. doi:10.1016/S0360-1315(01)00075-6.

Davis, J. A. (1966). The campus as a frog pond: An application of the theory of relative deprivation to career decisions of college men. American Journal of Sociology, 40, 1-10.

Davis, G. A., \& Rimm, S. B. (1985). Education of the gifted and talented. Englewood Cliffs: Prentice-Hall.

Dillenbourg, P. (2002). Over-scripting CSCL: The risks of blending collaborative learning with instructional design. In P. A. Kirschner, W. Jochems, P. Dillenbourg, \& G. Kanselaar (Eds.), Three worlds of CSCL: Can we support CSCL? (pp. 61-91). Heerlen: Open University.

Durkin, D. (1966). Children who read early. New York: Teachers College Press.

Earle, R. S. (2000). Standards for the accreditation of programs in educational communications and instructional technology (ECIT) (4th ed.). Bloomington: Association for Educational Communications and Technology, rev. October 2001.

Ely, D. P. (1999). Conditions that facilitate the implementation of educational technology innovations. Educational Technology, 39(6), 23-27.

European Commission (2005). Key data on education in Europe 2005. Luxembourg: Office for Official Publications of the European Communities (see also http://europa.eu.int).

Finn-Stevenson, M., \& Stern, B. M. (1997). Integrating early-childhood and family-support services with a school improvement process: The Comer-Zigler initiative. The Elementary School Journal, 98(1), 51-66. doi:10.1086/461884.

Gagné, R. M. (1965). The conditions of learning. London: Holt, Rinehart, \& Winston.

Gallagher, J. J. (1975). Teaching the gifted child. Boston: Allyn and Bacon.

Gardner, J. W. (1961). Excellence. Can we be equal and excellent too. New York: Harper.

Garnier, H. E., Stein, J. A., \& Jacobs, J. E. (1997). The process of dropping out of high school: A 19-year perspective. American Educational Research Journal, 34(2), 395-419.

Gillies, R. M. (2004). The effects of cooperative learning on junior high school students during small groups learning. Learning and Instruction, 14(2), 197-213. doi:10.1016/S0959-4752(03)00068-9.

Goleman, D. (1995). Emotional intelligence. New York: Bantam Books.

Grayson, J. P. (2001). The performance of 'gifted' high school students in university. The Canadian Journal of Higher Education, 31(1), 121-139.

Gustafson, K. (2002). Instructional design tools: A critique and projections for the future. Educational Technology Research and Development, 50(4), 59-66. doi:10.1007/BF02504985.

Hepler, J. B. (1998). Social integration of children with emotional disabilities and nonhandicapped peers in a school setting. Early Child Development and Care, 147, 99-115. doi:10.1080/ 0300443981470110 .

Hille, E. T. M., Den Ouden, A. L., Bauer, L., Van den Oudenrijn, C., Brand, R., \& Verloove-Vanhorick, S. P. (1994). School performance at nine years of age in very premature and very low birth weight infants: Perinatal risk factors and predictors at five years of age. The Journal of Pediatrics, 125(3), 426-434. doi:10.1016/S0022-3476(05)83290-1. 
Howard, E. R., \& Jenkins, J. M. (1970). Improving discipline in the secondary school. A catalogue of alternatives to repression. Denver: CFK.

James, M., Black, P., McCormick, R., Pedder, D., \& Wiliam, D. (2006). Learning how to learn, in classrooms, schools and networks: Aims, design and analysis. Research Papers in Education, 21(2), 101-118. doi:10.1080/02671520600615547.

Jervis, A., \& Gkolia, C. (2005). 'The machine stops': One school's rejection of integrated learning systems. Education and Information Technologies, 10(4), 305-321. doi:10.1007/s10639-005-3429-1.

Kalyuga, S., Ayres, P., Chandler, P., \& Sweller, J. (2003). The expertise reversal shift. Educational Psychologist, 38(1), 23-31. doi:10.1207/S15326985EP3801 4.

Kaplan, A., Gheen, M., \& Midgley, C. (2002). Classroom goal structure and student disruptive behaviour. The British Journal of Educational Psychology, 72, 191-211. doi:10.1348/000709902158847.

Kemp, J. E. (2000). An interactive guidebook for designing education in the 21st century. Bloomington: Technos Press of the Agency for Instructional Technology (AIT)/Association for Educational Communications and Technology (AECT).

Kensing, F., Simonsen, J., \& Bødker, K. (1998). MUST: A method for participatory design. HumanComputer Interaction, 13, 167-198. doi:10.1207/s15327051hci1302 3.

Kliewer, C., Fitzgerald, L. M., Meyer-Mork, J., Hartman, P., English-Sand, P., \& Raschke, D. (2004). Citizenship for all in the literate community: An ethnography of young children with significant disabilities in inclusive early childhood settings. Harvard Educational Review, 74(4), 373-402.

Kounin, J. S. (1970). Discipline and group management in classrooms. New York: Holt, Rinehart and Winston.

Kreijns, K., Kirschner, P. A., \& Jochems, W. (2003). Identifying the pitfalls for social interaction in computer-supported collaborative learning environments: A review of the research. Computers in Human Behavior, 19, 335-353. doi:10.1016/S0747-5632(02)00057-2.

Lipponen, L., Rahikainen, M., Hakkarainen, K., \& Palonen, T. (2002). Effective participation and discourse through a computer network: Investigating elementary students' computer supported interaction. Journal of Educational Computing Research, 27(4), 355-384. doi:10.2190/MGTWQG1E-G66E-F3UD.

Loeber, R., \& Farrington, D. P. (2001). The significance of child delinquency. In R. Loeber, \& D. P. Farrington (Eds.), Child delinquents: Development, intervention, and service needs (pp. 1-22). Thousand Oaks: Sage.

Lundy, L., \& Kilpatrick, R. (2006). Children's rights and special educational needs: Findings from research conducted for the Northern Ireland Commissioner for Children and Young People. Support for Learning, 21(2), 57-63. doi:10.1111/j.1467-9604.2006.00405.x.

Mangione, P. K., \& Speth, T. (1998). The transition to elementary school: A framework for creating early childhood continuity through home, school, and community partnerships. The Elementary School Journal, 98(4), 381-397. doi:10.1086/461903.

Marsh, H. W., Chessor, D., Craven, R., \& Roche, L. (1995). The effects of gifted and talented programs on academic self-concept: The big fish strikes again. American Educational Research Journal, 32(2), 285-319.

Marshall, B., \& Drummond, M. J. (2006). How teachers engage with assessment for learning: Lessons from the classroom. Research Papers in Education, 21(2), 133-149. doi:10.1080/ 02671520600615638.

Meijer, C. J. W. (2003). Inclusive education and effective classroom practices. Middelfart: European Agency for Development in Special Needs Education.

Meijer, C., Soriano, V., \& Watkins, A. (2003). Special needs education in Europe. Thematic publication. Middelfart: European Agency for Development in Special Needs Education.

Merrill, M. D. (2002). First principles of instruction. Educational Technology Research and Development, 50(3), 43-59. doi:10.1007/BF02505024.

Mönks, F. J., \& Lehwald, G. (1991). Neugier, Erkundung und Begabung bei Kleinkindern. München: Reinhardt.

Mooij, T. (1992). Predicting (under)achievement of gifted children. European Journal for High Ability, 3 (1), 59-74. doi:10.1080/0937445920030106.

Mooij, T. (1999a). Integrating gifted children into kindergarten by improving educational processes. Gifted Child Quarterly, 43(2), 63-74. doi:10.1177/001698629904300203.

Mooij, T. (1999b). Preventing antisocial behaviour of young children at risk. Risk Management: An International Journal, 1(2), 49-61. doi:10.1057/palgrave.rm.8240022.

Mooij, T. (1999c). Promoting prosocial pupil behaviour: 1: A multilevel theoretical model. The British Journal of Educational Psychology, 69(4), 469-478. doi:10.1348/000709999157842. 
Mooij, T. (1999d). Promoting prosocial pupil behaviour: 2: Secondary school intervention and pupil effects. The British Journal of Educational Psychology, 69(4), 479-504. doi:10.1348/ 000709999157851.

Mooij, T. (2000). Screening children's entry characteristics in kindergarten. Early Child Development and Care, 165, 23-40. doi:10.1080/0300443001650103.

Mooij, T. (2002). Designing a digital instructional management system to optimize early education. Educational Technology Research and Development, 50(4), 11-23. doi:10.1007/BF02504981.

Mooij, T. (2004). Optimising ICT effectiveness in instruction and learning: Multilevel transformation theory and a pilot project in secondary education. Computers \& Education, 42(1), 25-44. doi:10.1016/S0360-1315(03)00063-0.

Mooij, T. (2005). National campaign effects on secondary pupils' bullying and violence. The British Journal of Educational Psychology, 75(3), 489-511. doi:10.1348/000709904X23727.

Mooij, T., \& Driessen, G. (2008). Differential ability and attainment in language and arithmetic of Dutch primary school pupils. The British Journal of Educational Psychology, 78(3), 491-506.

Mooij, T., \& Smeets, E. (2006). Design, development and implementation of inclusive education. European Educational Research Journal, 5(2), 94-109. doi:10.2304/eerj.2006.5.2.94.

Mooij, T., Terwel, J., \& Huber, G. (2000). A social perspective on new learning. In R.-J. Simons, J. van der Linden, \& T. Duffy (Eds.), New learning (pp. 191-208). Dordrecht: Kluwer.

Morgan, A., \& Kennewell, S. (2005). The role of play in the pedagogy of ICT. Education and Information Technologies, 10(3), 177-188. doi:10.1007/s10639-005-2998-3.

National Conference of State Legislatures (2005). Task force on 'no child left behind': Final report. Washington, DC: National Conference of State Legislatures.

Nurmi, J.-E., \& Aunola, K. (2005). Task-motivation during the first school years: A person-oriented approach to longitudinal data. Learning and Instruction, 15(2), 103-122. doi:10.1016/j. learninstruc.2005.04.009.

Parkhurst, H. (1922). Education on the Dalton plan. New York: Dutton.

Perels, F., Gürtler, T., \& Schmitz, B. (2005). Training of self-regulatory and problem-solving competence. Learning and Instruction, 15(2), 123-139. doi:10.1016/j.learninstruc.2005.04.010.

Prins, F. J., Veenman, M. V. J., \& Elshout, J. J. (2006). The impact of intellectual ability and metacognition on learning: New support for the threshold of problemacity theory. Learning and Instruction, 16(4), 374-387. doi:10.1016/j.learninstruc.2006.07.008.

Purcell, J. H., Burns, D. E., Tomlinson, C. A., Imbeau, M. B., \& Martin, J. L. (2002). Bridging the gap: A tool and technique to analyze and evaluate gifted education curricular units. Gifted Child Quarterly, 46(4), 306-321. doi:10.1177/001698620204600407.

Reich, C., \& Young, V. (1975). Patterns of dropping out. Interchange, 6(4), 6-15. doi:10.1007/ BF02145343.

Reynolds, N. (2005). The computer as scaffold, tool and data collector: Children composing with computers. Education and Information Technologies, 10(3), 239-248. doi:10.1007/s10639-0053004-9.

Roelofs, E., \& Terwel, J. (1999). Constructivism and authentic pedagogy: State of the art and recent developments in the Dutch national curriculum in secondary education. Journal of Curriculum Studies, 31(2), 201-227. doi:10.1080/002202799183232.

Roelofs, E., Visser, J., \& Terwel, J. (2003). Preferences for various learning environments: Teachers' and parents' perceptions. Learning Environments Research, 6, 77-110. doi:10.1023/A:1022915910198.

Rozendaal, J. S., Minnaert, A., \& Boekaerts, M. (2005). The influence of teacher perceived administration of self-regulated learning on students' motivation and information-processing. Learning and Instruction, 15(2), 141-160. doi:10.1016/j.learninstruc.2005.04.011.

Salmivalli, C., Kaukiainen, A., \& Voeten, M. (2005). Anti-bullying intervention: Implementation and outcome. The British Journal of Educational Psychology, 75(3), 465-487. doi:10.1348/ $000709905 \times 26011$.

Schnotz, W., \& Lowe, R. (2003). External and internal representations in multimedia learning. Learning and Instruction, 13(2), 117-123. doi:10.1016/S0959-4752(02)00015-4.

Schunk, D. H. (2005). Commentary on self-regulation in school contexts. Learning and Instruction, 15(2), 173-177. doi:10.1016/j.learninstruc.2005.04.013.

Scott, M. S., \& Delgado, C. F. (2003). Using educational placement in third grade to select and validate a pre-school screening measure. Psychology in the Schools, 40(6), 565-582. doi:10.1002/pits.10124.

Sinko, M., \& Lehtinen, E. (1999). The challenges of ICT in Finnish education. Atena: Jyväskylä. 
Skinner, D., Bryant, D., Coffman, J., \& Campbell, F. (1998). Creating risk and promise: children's and teachers' coconstructions in the cultural world of kindergarten. The Elementary School Journal, 98, 297-310. doi:10.1086/461897.

Spinath, B., \& Spinath, F. M. (2005). Longitudinal analysis of the link between learning motivation and competence beliefs among elementary school children. Learning and Instruction, 15(2), 87-102. doi:10.1016/j.learninstruc.2005.04.008.

Sternberg, R. J., \& Grigorenko, E. L. (2002). The theory of successful intelligence as a basis for gifted education. Gifted Child Quarterly, 46(4), 265-277. doi:10.1177/001698620204600403.

Triantafillou, E., Pomportsis, A., \& Demetriadis, S. (2003). The design and the formative evaluation of an adaptive educational system based on cognitive styles. Computers \& Education, 41, 87-103. doi:10.1016/S0360-1315(03)00031-9.

Tymms, P., Merrell, C., \& Henderson, B. (2000). Baseline assessment and progress during the first three years at school. Educational Research and Evaluation, 6(2), 105-129. doi:10.1076/1380-3611 (200006)6:2;1-E;F105.

Underwood, J. D. M. (2003). Student attitudes towards socially acceptable and unacceptable group working practices. The British Journal of Psychology, 94, 319-337. doi:10.1348/ 000712603767876253.

US Department of Health, Education and Welfare (1973). Positive approaches to dropout prevention. Washington: US Government Printing Office.

Van den Boom, G., Paas, F., Van Merriënboer, J. J. G., \& Van Gog, T. (2004). Reflection prompts and tutor feedback in a web-based learning environment: Effects on students' self-regulated learning competence. Computers in Human Behavior, 20, 551-567. doi:10.1016/j.chb.2003.10.001.

Van Merriënboer, J. J. G. (1997). Training complex cognitive skills: A four-component instructional design model for technical training. Englewood Cliffs: Educational Technology.

Veenman, M. J. V., Wilhelm, P., \& Beishuizen, J. J. (2004). The relation between intellectual and metacognitive skills from a developmental perspective. Learning and Instruction, 14(1), 89-109. doi:10.1016/j.learninstruc.2003.10.004.

Walker, H. M., Kavanagh, K., Stiller, B., Golly, A., Severson, H. H., \& Feil, E. G. (1998). First step to success: An early intervention approach for preventing school antisocial behavior. Journal of Emotional and Behavioral Disorders, 6(2), 66-80.

Watkins, A. (2001). Information and Communication Technology (ICT) in Special Needs Education $(S N E)$. Brussels: European Agency for Development in Special Needs Education, Accessed August 30th 2005. http://www.european-agency.org.

Wilson, B. G. (1999). Evolution of learning technologies: From instructional design to performance support to network systems. Educational Technology, 39(2), 32-35.

Zakopoulos, V. (2005). An evaluation of the quality of ICT teaching within an ICT-rich environment: The case of two primary schools. Education and Information Technologies, 10(4), 323-340. doi:10.1007/ s10639-005-3430-8.

Zimmerman, B. J. (2000). Attaining self-regulation: A social cognitive perspective. In M. Boekaerts, P. R. Pintrich, \& M. Zeidner (Eds.), Handbook of self-regulation (pp. 13-41). San Diego: Academic.

Zimmerman, B. J. (2002). Achieving academic excellence: A self-regulatory perspective. In M. Ferrari (Ed.),The pursuit of excellence through education (pp. 85-110). Hillsdale: Erlbaum. 